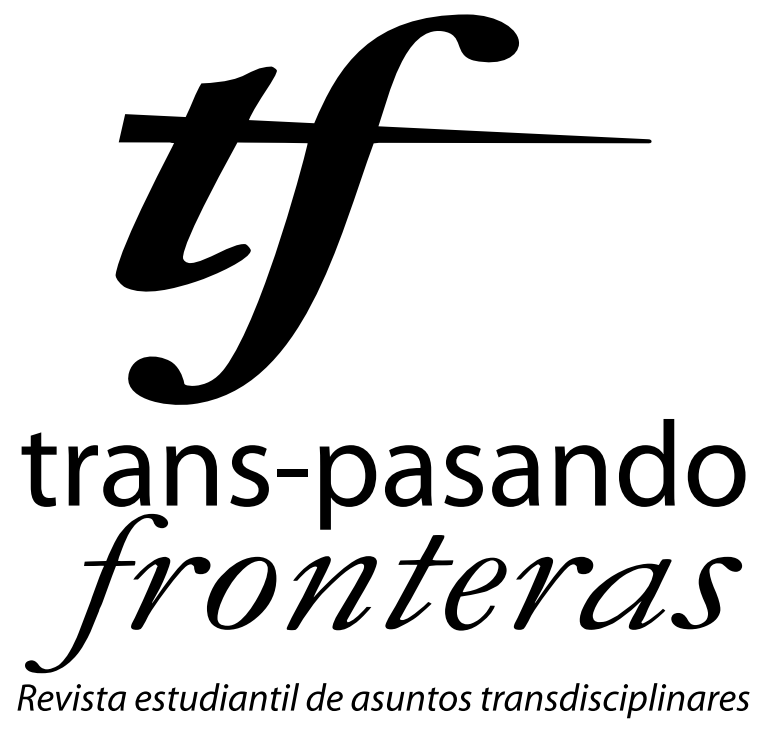

Una publicación de

Facultad de Derecho y Ciencias Sociales

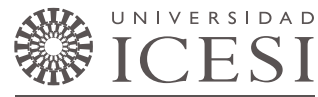




\title{
¿Primavera de mujeres?
}

\author{
Mónica Castillo* \\ (monicastillo26@yahoo.es)
}

Reporte de caso recibido el 18/06/2012 y aprobado el 17/10/2012.

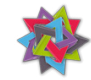

Como citar este artículo:

CASTILLLO CUBILLO, Mónica (2012). “PPrimavera de mujeres?”. En: Trans-pasando Fronteras, Núm. 2, pp. 87-95. Cali, Colombia: Centro de Estudios Interdisciplinarios, Jurídicos, Sociales y Humanistas (CIES), Universidad Icesi.
\end{abstract}

\begin{abstract}
Resumen
Términos tales como "feminismo islámico" y "movimiento de mujeres" hacen alusión a los movimientos sociales de mujeres que buscan reivindicar sus derechos en medio de sociedades fuertemente represivas. Sin duda, esta defensa por los derechos posee una gran influencia Occidental. Sin embargo, lo que se busca en este breve estudio es describir algunos movimientos sociales de mujeres y presentar una visión general del papel y la participación de las mujeres en la Primavera Árabe por medio de un breve estudio documental, analizando noticias, eventos, artículos de prensa y de opinión. Dada la importancia que se le ha atribuido a las redes sociales como motores de la revolución, también se intentará enfatizar en la perspectiva de las redes sociales y el papel de las mujeres en estas, su representación, protagonismo, victimización e invisibilización.
\end{abstract}

\section{Palabras clave}

Feminismo islámico, Feminismo musulmán, Movimiento de mujeres, Revoluciones árabes, Primavera árabe

* Estudiante de noveno semestre de Sociología y Antropología de la Universidad Icesi. Sus áreas de interés son la sociología del trabajo, los movimientos sociales y la intervención social. Ponente en el IX Congreso Nacional de Estudiantes de Sociología con el trabajo "Fundamentación y apropiación de los derechos (estado y comunidad)del pueblo indígena Misak/Guambian”. Es asistente académica y de investigación del área de Estudios Sociales de la Universidad Icesi. 


\section{Introducción}

Términos como "Feminismo islámico", "feminismo musulmán”, "movimientos de mujeres", son algunas de las categorías para conceptualizar y nombrar aquellos movimientos sociales de mujeres que buscan reivindicar sus derechos, en medio de sociedades islámicas fuertemente "represivas", que en nombre de un dios todopoderoso y de lo expuesto en el libro sagrado del Corán, pretenden dominar a través de su contenido religioso (y moral) todas las esferas de la vida social de la mujer, lo laboral, la familia, la política y la cultura.

El feminismo islámico y los movimientos de mujeres, como ideologías de la liberación, buscan reivindicar el papel de las mujeres en el mundo árabe, pretende la igualdad de género en el contexto privado y público, propende por los derechos laborales, educativos, culturales, políticos (democráticos) de la mujer, estos se derivan de la influencia de los discursos feministas en Occidente, de la imagen y el papel de la mujer "libre" de ataduras, trajes (el hiyab), estereotipos, representaciones, valores y contenidos religiosos y morales que inhiban su realización personal. Los esfuerzos de las feministas van desde reinterpretaciones del Corán, críticas al papel subordinado de la mujer, producciones intelectuales como artículos, libros, entre otros, luchas en la esfera política y legislativa, y movilizaciones sociales. Estos esfuerzos han encontrado grandes opositores y obstáculos que han impedido su realización, por la misma forma en que se concibe a la mujer en la cultura islam, y por el creciente fundamentalismo en algunos de los países árabes.

Para este breve estudio, he querido centrarme en las movilizaciones sociales de las mujeres en el marco de la llamada primavera árabe, vivida en el mundo árabe en el último año (2011), es así como me propongo realizar un panorama general del papel y la presencia de las mujeres en la primavera árabe, enfocándome en algunos países del mundo árabe: Egipto, Libia y Yemen. Esto a la luz del fenómeno de las redes sociales como aparentes impulsores de la revolución. Para ello intentaré primero, indagar algunos textos y artículos académicos sobre movimientos sociales en la Red, nuevas revoluciones árabes y nuevos repertorios tecnológicos de comunicación; segundo, analizar noticias, hechos, artículos de prensa, de opinión que permitan dar un panorama del papel y participación de mujeres y feministas en la primavera árabe; y tercero, terminar con unas breves conclusiones sobre el tema. 


\section{Revoluciones árabes y nuevos repertorios tecnológicos de comunicación}

Las nuevas revueltas o revoluciones presentadas en el mundo árabe en el último año, son a mí parecer una de las expresiones más grandes de la influencia de las redes sociales en los movimientos gestados. Estos, tienen como grandes protagonistas a los jóvenes de diferentes países islámicos, y obedecen a múltiples procesos y lógicas dependiendo de los países y las zonas donde estas se han llevado a cabo, así como de sus complejidades políticas, culturales y económicas, en los que las oposiciones a los regímenes políticos existentes parecen ser una constante.

Por otra parte, en un mundo cada vez más mediado por los nuevos repertorios tecnológicos de comunicación, estos se convierten en escenarios cada vez más importantes para la vida de sus usuarios; internet es tal vez la expresión máxima de estos repertorios, o mejor es aquí donde se expresan múltiples fenómenos comunicativos que están transformando el mundo, la gran cantidad de información (de todo tipo) que "alli'" podemos encontrar; la velocidad de comunicarnos a pequeñas o grandes distancias alrededor del globo; y el fenómeno de las redes sociales, comunidades virtuales que traspasan las fronteras fisicas y las barreras del tiempo y espacio, a través de las cuales interactuamos, nos comunicamos y compartimos con otros cotidianamente, y donde seguramente muchos nos convertimos en "militantes" políticos, donde impulsamos movimientos sociales, nos "movilizamos", y creamos nuevos repertorios de acción.

Pero, es el paso de la vida on-line a la vida off-line donde realmente existen posibilidades para el cambio social y es precisamente esto lo que ha ocurrido en la primavera árabe. Según Tamayo y et al (2001) la emergencia de estos nuevos movimientos sociales en la Red, surgen como una salida al discurso neoliberal globalizado que a finales de la década de años 90 tuvo su punto cumbre con las protestas en Seattle (EE.UU.). A partir de entonces, se inicia una nueva etapa de activación social a escala global, donde convergen fuerzas sociales diversas pero que coinciden en la idea de que existe(n) "otro(s) mundo(s) posible(s)", y es esta idea, la de un nuevo mundo posible, la que en parte nos ayuda a entender la primavera árabe y el papel de las mujeres en ella.

Esto permitió el surgimiento de un escenario de acción política, donde según Viviam Unás (2011), se propone la emergencia de una nueva forma de hacer política: la política menor o la subpolítica (en oposición a una política mayor), como alternativas al sistema 
político tradicional del Estado, adscritos a múltiples proyectos y objetivos, a partir de iniciativas de los ciudadanos comunes. Según la autora, estos movimientos se definen en

\footnotetext{
"clave de cinco puntos: a) Son movimientos que se fundan en la difusión de proyectos y códigos culturales diversos; b) una de sus preocupaciones más sentida es la visibilización de conflictos sociales y la denuncia a través del discurso;c) se coordinan a través de estructuras reticulares y flexibles; d) acuden a acciones simbólicas y actos performativos; y e) se fundan en una profunda politización de lo social, lo cultural y la vida cotidiana” (Unás, 2011:3).
}

Por lo anterior, el movimiento feminista y de mujeres en la primavera árabe puede inscribirse más a una política menor que a una mayor, pues busca un mundo posible, a través de múltiples proyectos y objetivos relacionados con los derechos de las mujeres, traspasando los límites del espacio y tiempo a través de internet, va más allá de las diversidades culturales de sus "militantes", es un movimiento de denuncia y visibilización de una problemática, politiza las acciones cotidianas de los individuos en relación con sus derechos, así como las "tradiciones" culturales (concepciones de la mujer), a través de acciones simbólicas: manifestaciones, marchas, denuncias públicas.

No obstante, según González (2011), las revueltas árabes dependen de un "nuevo sistema mediático" y no sólo del papel las redes sociales, así como de unas realidades económicas, sociales y políticas comunes, y diferentes entre los países del mundo árabe. De igual manera, es importante resaltar "los límites del ciberactivismo árabe", pues las transformaciones sociales y políticas se encuentran en relación con un nivel mínimo de "aculturación digital", esto es, que a pesar de que existe un crecimiento importante en la penetración de estas nuevas tecnologías en países como Egipto, Túnez y Yemen, estas siguen siendo marginales en comparación con la población total.

No obstante, existe un proceso acelerado de "transición digital" en la mayoría de las sociedades árabes, en el que las redes sociales no sólo tiene repercusiones políticas sino que se constituyen en "comunidades virtuales organizadas en muchedumbres inteligentes” (González, 2011:5). Por otra parte, se le ha adjudicado a redes sociales como Facebook y Twitter un papel definitivo en la caída de los regímenes, así como un papel liberador, no obstante, ante la marginalidad del acceso a estas nuevas tecnologías y la 
posibilidad de que los gobiernos pueden a través de ellas vigilar, constreñir y contener a los revolucionarios, esto puede ponerse en duda. A esto se le suma además que estas redes no son neutrales, ni hay libertad total de los flujos de la información, así como desigualdad en la circulación y el acceso a la misma. (González, 2011).

Por esto, González (2011) dirá que este "nuevo sistema mediático" se compone de una serie acontecimientos que van desde la década de 1980 como son: el lanzamiento de periódicos panárabes como Al-Hayat y Al-Sharq al-Awsat; la creación de cadenas satelitales a partir de la década de 1990; y en la última década el surgimiento de innovaciones tecnológicas, como blogs y redes sociales. Todo ello permite que surja un "nuevo sistema mediático", que a su vez impulsó, y sigue impulsando, la primavera árabe.

\section{El activismo femenino en el mundo árabe}

Lo cierto es que las mujeres no sólo han participado activamente en las revoluciones, sino que no habría sido posible que las mismas se produjeran $\sin$ los profundos cambios que en los últimos diez años han estado produciéndose en las sociedades de mayoría de población árabe.

Estas revoluciones, fruto de la insostenible situación de represión, desigualdad, crisis, pobreza, falta de derechos humanos y de cualquier perspectiva de futuro, atienden a la aspiración de unas poblaciones que cuando pronuncian "el pueblo quiere que caiga el régimen", no se están limitando a hacer referencia a las estructuras políticas dictatoriales, sino al conjunto de estructuras, políticas, sociales, económicas y culturales, que reforzándose las unas en las otras, y que han perpetuado las injusticias y la represión en todos los niveles de la vida socio-política, afectando a todos los individuos sin distinción de clase, sexo, raza o etnia (Adlbi, 2011:18)

Según Adlbi (2011), las mujeres han tenido un papel fundamental en la llamada primavera árabe con la visibilización y voz de activistas y feministas que se han manifestado en la esfera pública, y que han adquirido cierto "status" para la comunidad nacional e internacional, como es el caso en Yemen de Tawakkul Karman, detenida en la Plaza de Sanaa por protestar contra el régimen y por ser una de las gestoras que ayudó a formar la agrupación femenina opositora al régimen "sin cadenas", tras su liberación se ha constituido en una de 
las mujeres más sobresalientes, por lo que en Septiembre de este año fue galardonada con un Premio Nobel de Paz; en Libia, "Iman El Obeydi fue violada 15 veces por los hombres al servicio de Gadafi , y tuvo el valor de entrar en el hotel Rixon en Trípoli donde se concentraban periodistas y medios de comunicación y denunciar su situación” (Adlbi, 2011:17); en Egipto también se muestran una presencia importante de mujeres en la Plaza de Tahrir, "donde se destaca Sali Zahran, asesinada en uno de los ataques del régimen a la Plaza y Asma Mahfouz, una de las fundadoras del 'Movimiento 6 de abril' y una de las más sobresalientes voces que llamaron a la rebelión” (Adlbi, 2011:17).

Pero además de existir personajes sobresalientes en las revueltas; el papel de las mujeres en estas movilizaciones ha sido el de agentes de lucha, de denuncia, a través del discurso y la movilización a favor no sólo de sus derechos sino unidas a un interés común mayor como es el de la sociedad civil que protesta por mejores condiciones políticas, económicas y sociales.

Por otra parte, dirá Adlbi (2011) que las mujeres han sido "objeto" de represiones por parte de los regímenes políticos, siendo encarceladas, maltratadas, criminalizadas, etc.; además de que se ha intentado invisibilizar su papel, en algunos medios de comunicación. Lo que puede constatarse en diversas noticas y artículos de medios de comunicación, donde se visibilizan y denuncian casos las violaciones, maltratos, realizados en contra de las manifestantes, un ejemplo de ello son las denuncias de Amnistía Internacional y el Parlamento Europeo debido a la tortura de 18 mujeres en la Plaza Tahir, en Egipto en marzo, "que tras ser golpeadas indiscriminadamente, se les obligó a hacer la prueba de virginidad, bajo la amenaza de que las que no fueran vírgenes serían acusadas de prostitución o la paliza que recibió la periodista de la CBS, Sara Logan mientras la desnudaban y atacaban sexualmente" (Rivas, 2011).

En diversos artículos y noticias se destaca también el papel de las asociaciones y movimientos femeninos para impulsar la movilización y ejercer presión por la democratización de la sociedad civil en estos países, así como la importancia de cambios gestados desde décadas anteriores que han encontrado en la primavera árabe su punto cumbre y, a ello se le suman condiciones sociales y económicas muy complejas, pobreza, exclusión, marginalidad, represión, crisis económicas, violaciones a los derechos humanos. 
"Las mujeres han sido y siguen siendo protagonistas de las revoluciones de la región y están física y masivamente presentes en la calle, lo cual es fundamental”, estimó Nadim Hury, investigador de la organización de defensa de los Derechos Humanos, Human Rights Watch (HRW). "Es una señal de esperanza", agregó, recalcando que las mujeres también "tendrían que ser protagonistas en las nuevas instituciones que nazcan de estas revoluciones” (Anónimo, 2011)

Es así como, numerosas noticias y artículos destacan el protagonismo de las mujeres en estas nuevas revoluciones árabes como gestoras del cambio, como una oportunidad para el futuro, una revolución para las mujeres (Frenkel, 2011) y hacen alusión a la ruptura de normas sociales culturalmente aceptadas en las manifestaciones, el uso de otro tipo de ropas y expresiones. Así mismo, el uso de internet y de estos nuevos repertorios tecnológicos de comunicación ha sido fundamental, pues a través de estos las mujeres hacen llamados para la movilización y denuncian situaciones de injusticia, tal es el caso Asmaa Mahfouz, una activista que hace a través de Youtube y Facebook hace llamamientos a otros egipcios para movilizarse ${ }^{1}$.

Ante esta situación, se plantea la importancia de los retos que deben enfrentar las mujeres y del papel que deben desempeñar para beneficiarse de las nuevas oportunidades que puedan presentárseles durante y después de la revolución, para acceder a la esfera pública, política, laboral y seguir luchando por sus derechos.

Es interesante notar que al buscar imágenes en google sobre las revoluciones árabes donde se muestran mujeres, en muchas de estas las mujeres aparecen separadas de los hombres en algunas de las manifestaciones en Libia y Egipto.

Para finalizar, otra de las cuestiones a resaltar, es el hecho de que la mayoría de noticas y artículos que se encuentran sobre el papel y la participación de las mujeres, son del primer semestre del 2011, pareciera entonces que su importancia hubiera pasado a un segundo plano, o que su participación y papel no es igual de fuerte como lo sí fue en los primeros meses del año.

1 Ver: Meet Asmaa Mahfouz and the vlog that Helped Spark the Revolution, disponible en: http://www. youtube.com/watch?v=SgjIgMdsEuk 


\section{Conclusiones}

A manera, de conclusión podría decirse que por lo menos desde diversos puntos de vista de académicos y de medios de comunicación, el papel y la participación de la mujer en la primavera árabe han sido positivos, y que estos se han destacado principalmente en el primer semestre de 2011. Estas acciones dependen en buena medida de unas condiciones económicas, políticas, laborales y culturales desfavorables donde la marginalidad, la exclusión y la violación de los derechos humanos parece ser una constante no sólo para las mujeres, sino para la sociedad en general, principalmente, los jóvenes.

La imagen de la mujer como victima y al mismo tiempo luchadora sale a relucir, como una mezcla entre sumisión y rebeldía, con su cuerpo y cabeza cubiertas pero saliendo a la calle, gritando y exigiendo su reivindicación, un cambio para ellas y para los ciudadanos de su país. Su papel en la primavera árabe, es ante todo un papel político y su accionar puede considerase como formas de subpolítica y política menor, según lo planteado por Unás (2011), en la medida en que buscan visibilizar conflictos sociales a través de la denuncia, se han coordinado desde estructuras flexibles haciendo uso de medios como Facebook, YouTube, entre otros, acuden a actos simbólicos como marchas, movilizaciones, pancartas que politizan las acciones cotidianas.

Quedan entonces hasta ahora dos interrogantes, ¿Cuál es el papel actual de la mujer en la primavera árabe, en luchas y movilizaciones? y ¿Cuál es el futuro que le espera a las mujeres después de dichas revoluciones, mejorará su situación, se cumplirán sus derechos y reivindicaciones? ¿Qué tan efectivas serán estas acciones para implicar cambios sociales importantes?

\section{Bibliografía}

ADLBI, Sirin. (2011). "Mujeres, revoluciones árabes y colonialidad". En: Revista Solidaridad Internacional, No. 60, pp. 16-18. Taller de Estudios Internacionales Mediterráneos (TEIM)

AFARY, Janet. (2000). "Feminismo y fundamentalismo”. En: Oriente próximo: genocidio, autodeterminación, literatura, feminismo. Madrid: Ediciones Akal. No.6

ANÓNIMO (2011). "Las mujeres, protagonistas de las revoluciones árabes”. En El nuevo diario. Recuperado 25 de Septiembre de 2011, desde http://www.elnuevodiario. com.ni/internacionales/96395 
BOYES, Roger (2011). "Nobel Peace Prize judges honour African women's struggles". En The Times. Recuperado 1 de Noviembre de 2011, desde http://www.thetimes. co.uk/tto/news/world/africa/article3187228.ece

FATMA, Naib. (2011). "Karman: Peaceful revolution 'only solution"”. En: Aljazeera. Recuperado 5 de Noviembre de 2011, desde http://www.aljazeera.com/indepth/features/2011/10/2011107172033851656.html

FRENKEL, Sheera. (2011). "Rise of Islamists draws a veil over women's hopes for fairer future". En: The Time. Recuperado 25 de Septiembre de 2011, desde http://www. thetimes.co.uk/tto/news/world/middleeast/article3109836.ece

GONZÁLEZ-QUIJANO, Yves (2011). "Las revueltas árabes en tiempos de transición digital”. En: Revista Nueva Sociedad, No. 235. pp. 4-7

RIVAS, Mercé. (2011). Las mujeres y las revoluciones árabes. Diario sur. Recuperado 5 de Noviembre de 2011, desde http://www.diariosur.es/v/20110716/opinion/ mujeres-revoluciones-arabes-20110716.html

TAMAYO, Eduardo, Osvaldo León y Sally Burch (2001). Movimientos sociales en la Red. Quito: Agencia Latinoamericana de Información (ALAI).

TOHIDI, Nayered. (2008). "Feminismo islámico: Negociando el patriarcado y la modernidad". En: Suarez-Navaz, L. y Hernandez, R. Descolonizando el feminismo. Teorías y prácticas desde los márgenes, pp. 245-279. Madrid: Ediciones Catédra.

UNÁS, Viviam. (2011). "Nuevos Repertorios Tecnológicos y Movimientos Sociales: El caso de la Asociación Indígena del Norte del Cauca (ACIN)". En: Revista CS, No. 6. Cali: Universidad Icesi 